\title{
PMMA nanocomposites with graphene oxide hybrid nanofillers
}

\author{
J. Sanes, G. Ojados, R. Pamies, M. D. Bermúdez* \\ Grupo de Ciencia de Materiales e Ingeniería Metalúrgica. Universidad Politécnica de Cartagena. Campus de la Muralla \\ del Mar. C/ Doctor Fleming s/n. 30202-Cartagena, Spain
}

Received 3 April 2019; accepted in revised form 26 May 2019

\begin{abstract}
Polymethylmethacrylate (PMMA) and nanocomposites containing 0.5 wt.\% graphene oxide (GO), graphene oxide-multiwalled carbon nanotubes (NT) or graphene oxide-ionic liquid 1-octyl-3-methylimidazolium tetrafluoroborate (IL) (PMMA+GO; PMMA+GO-NT; PMMA+GO-IL) were processed by a single step twin-screw micro-extrusion. The effect of two extrusion temperature profiles and two specific mechanical energy ( $S M E)$ values has been studied. Results of Raman spectroscopy, scanning electron microscopy (SEM) and transmission electron microscopy (TEM), energy dispersive $\mathrm{X}$-ray analysis (EDX), X-ray diffraction (XRD), and X-ray photoelectron spectroscopy (XPS) analysis show changes in GO composition and morphology, and better dispersion due to interaction with IL. Dynamic mechanical analysis shows that extrusion conditions affect storage modulus of hybrid nanocomposites. Rheological measurements show that the complex viscosity of the nanocomposites is higher than that of PMMA at low shear rates for materials processed under the lower value of SME. A maximum viscosity increase of $62.6 \%$ is found for PMMA+GO-NT. The lowest increase found for PMMA+GOIL, is attributed to the better dispersion of the hybrid GO-IL nanofiller.
\end{abstract}

Keywords: nanocomposites, graphene oxide, microextrusion, dynamic-mechanical properties, rheology

\section{Introduction}

Polymer/carbon nanofiller nanocomposites are receiving increasing attention $[1-8]$ in the expectation of improving the stability and mechanical, tribological or degradation resistance of polymer matrices by the addition of dispersed carbon nanotubes or graphene nanofillers as neat, modified or functionalized nanomaterials [9-17]. The unique characteristics of carbon nanostructures may considerably enhance the performance of the composite materials with respect to polymer matrices.

Although numerous thermoplastic matrices have been modified by the addition of graphene nanofillers [5, 18], only a few of them [19-21] use the melt blending process without a previous step of mixture in solution. On the other hand, additive proportions are usually higher than 1\% [22]. In particular, Vallés et al.
[20] described the preparation of PMMA/GO nanocomposites with an additive proportion between 0.5 and $10 \mathrm{wt} \%$ processed by melt mixing using a twinscrew extruder, but applying repeated extrusion cycles.

PMMA nanocomposite containing $0.5 \mathrm{wt} \% \mathrm{GO}$ has been prepared in the present work and compared with $\mathrm{PMMA}+\mathrm{GO}$ previously modified by ionic liquid and with PMMA containing a mixture of GO and multiwalled carbon nanotubes. The main reasons to choose these materials are summarized below.

While graphene layers in GO are hydrophobic, the oxygen-containing functional groups present at the surface of GO are hydrophilic. This amphiphilic nature is an advantage for the dispersion of GO platelets in the matrix of polymers with polar groups such as PMMA. Nevertheless it is still difficult to disperse 
GO in polymer matrices owing to the formation of large aggregates. In order to avoid this problem, a common practice is surface modification. Surface modification to improve dispersion and compatibility with the matrix can be achieved by the addition of an ionic liquid [23]. The synergy of ionic liquid and nanofillers has previously shown its efficacy [24-27].

Ionic liquids (ILs) are molten salts [28] formed by bulk organic cations and organic or inorganic anions which are in the liquid state at room temperature, and show a unique combination of properties such as their low volatility, non-flammability, and their high thermal stability which are most relevant for a wide range of applications.

The ability of ILs to modify, disperse and functionalize [29] carbon nanotubes has given rise to a new family of nanofluids [30] and nanomaterials.

Zhou et al. [31], showed that graphene layers can disperse in the ionic liquid 1-butyl-3-methylimidazolium hexafluorophosphate through non-covalent functionalization. Yang et al. [23] have used ionic liquid-functionalized graphene as nanoreinforcement of in situ polymerized PMMA matrix increasing electrical conductivity, thermal stability and storage modulus with respect to the neat polymer. Imidazolium ILs were able to form non-covalent $\pi-\pi$ and cation- $\pi$ interactions with graphene surfaces, while ILs containing vinyl groups attached to graphene oxide sheet edges through ion-exchange.

Recently, Fang et al. [32] have described the effect of ILs on the rheology of PMMA/carbon nanotube nanocomposites, showing the effect of ILs on the improvement of carbon nanotube dispersion in the PMMA matrix.

We have very recently shown the good tribological performance and even self-healing behaviour of epoxy resin modified by the addition of high percentages of ionic liquid or low concentrations of graphene or graphene modified by ionic liquid [33].

In previous works, [34], we have reported the improved scratch resistance of new extruded and injected PMMA nanocomposites containing $1 \mathrm{wt} \%$ single-walled carbon nanotubes (SWCNT) or SWCNT modified by the IL 1-octyl-3-methylimidazolium tetrafluoroborate. This IL was selected to modify graphene oxide in the present study.

Another strategy is to use a combination of carbon nanofiller additives. Recent results have shown that GO layers and carbon nanotubes can combine through $\pi-\pi$ interactions. Yang et al. [35], used graphene nanoplatelets and multi-walled carbon nanotubes as additives of epoxy resin nanocomposites. Carbon nanotubes inhibit the aggregation of graphene nanoplatelets and, as a result, the nanocomposite materials reinforced with the hybrid nanofiller show enhanced mechanical and thermal properties with respect to those containing just one carbon nanofiller. Recently, Jyoti et al. [36], reported the improvement of the dynamic-mechanical properties of ABS nanocomposites containing GO-multiwalled carbon nanotubes hybrid nanofiller. This type of hybrid nanofiller has also been selected for the present study.

A single step twin-screw co-rotating micro-extrusion process has been used in the present work to obtain new PMMA nanocomposites with GO, GO-NT and GO-IL hybrid nanofillers. Extrusion is a common process for the preparation of polymers and polymers containing nanofillers such and nanoclays, carbon nanotube or graphene, however, the influence of the process parameters on the microstructure and properties of the materials has been scarcely studied $[22,37-48]$. We have studied nanocomposites processed using two temperature profiles and two specific mechanical energy values.

Specific mechanical energy ( $S M E)$ can be defined as a measure of the mechanical energy which is transferred to the material, per mass unit, during extrusion [46]. This magnitude has been used to establish the influence of extrusion parameters (temperature, screw rotation speed, flow rate, feeding rate, etc.) on the dispersion of nanofillers in polymer nanocomposites. Domenech et al. [46] have highlighted the importance of $S M E$ in melt processing with respect to the final structure and properties of nanocomposite materials. In particular, a high $S M E$ can optimize twinscrew extrusion of nanocomposites. Mechanical and thermal properties of the extruded polymers are related to $S M E$ values.

Rheological properties of polymer nanocomposites are determined by the structure and morphology of dispersed nanofillers, their interaction with the polymer matrix and the processing conditions. Rheological studies are particularly relevant in the case of melt-processed materials [32, 49], as their results are related both to possible matrix degradation and to the degree of dispersion of the added nanofillers. With these precedents, the main objectives of the present study are to develop new graphene oxide/carbon nanotube or graphene oxide/ionic liquid hybrid 
nanocomposite materials in a simple way, by a single micro-extrusion step, and to determine the effect of the additives on their microstructure and on their rheological, thermal and dynamic-mechanical properties.

\section{Experimental}

PMMA (Plexiglas ${ }^{\circledR}$ ) was supplied by Evonik Industries AG, Germany. 1-octyl-3-methylimidazolium tetrafluoroborate IL ( $\geq 97 \%$ purity) (Figure 1), was purchased from Iolitec GmbH (Germany) Graphene oxide (GO) (av-GOX-40) was purchased from Avanzare Innovación Tecnológica, S.L. (Spain) (Figure 2) and presents 1-2 layers (approximate width $40 \mu \mathrm{m}$; approximate thickness $1--2 \mathrm{~nm}$ ), with $30 \%$ oxygen content and specific surface of $400 \mathrm{~m}^{2} / \mathrm{g}$.

Multi-walled carbon nanotubes (NT) (1204YL), 99\% purity, were purchased from Iolitec $\mathrm{GmbH}$ (Germany). The approximate dimensions are: $10-15 \mathrm{~nm}$ external diameter; 5-7 nm internal diameter; 10 $60 \mu \mathrm{m}$ length and specific surface $350-420 \mathrm{~m}^{2} / \mathrm{g}$.

GO-NT hybrid nanofiller was obtained by mixing GO $(3 \mathrm{~g})$ with NT $(1 \mathrm{~g})$ in $50 \mathrm{ml}$ ethanol. The mixture was sonicated for 1 hour, the solvent was removed by centrifugation, and the solid residue was dried in a vacuum oven at $60^{\circ} \mathrm{C}$ for 7 days.

IL-modified graphene oxide (GO-IL) was obtained by mechanical milling GO $(0.5 \mathrm{~g})$ with $\operatorname{IL}(1 \mathrm{~g})$ in an agate mortar for 10 minutes. The mixture was then sonicated for 1hour. Excess IL was eliminated by five successive steps of centrifugation and washing

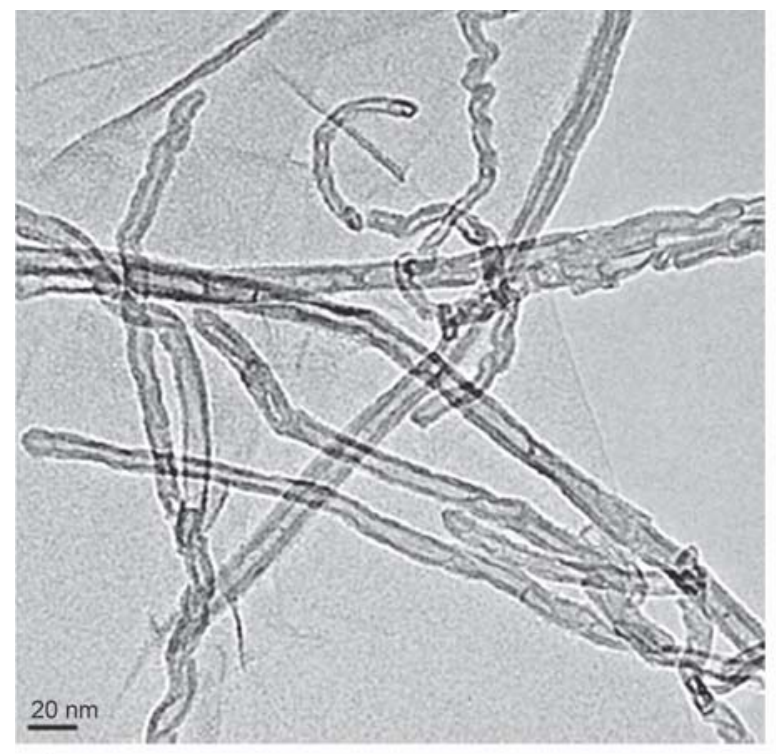

a) with acetonitrile. The solid was dried in a vacuum oven at $60^{\circ} \mathrm{C}$ for 7 days.

PMMA and nanocomposites containing $0.5 \mathrm{wt} \%$ nanofiller were milled in RESTCH ultracentrifuge mill at $10000 \mathrm{rpm}$, and dried in an oven before extrusion.

Thermogravimetric measurements were performed with a TGA 1HT (Mettler Toledo) equipment $\left(\mathrm{N}_{2}\right.$ flow $50 \mathrm{ml} / \mathrm{min}$; heating rate of $10^{\circ} \mathrm{C} / \mathrm{min}$ ), in the temperature range from room temperature to $800^{\circ} \mathrm{C}$. Dynamic-mechanical properties were determined with a Q800 dynamic mechanical analyzer (DMA) from TA Instruments. Cylinders (15 mm length; $1 \mathrm{~mm}$ diameter) were tested under the tensile configuration, between 35 and $170^{\circ} \mathrm{C}$, at a heating rate of $3{ }^{\circ} \mathrm{C} / \mathrm{min}$, with a frequency of $1 \mathrm{~Hz}$. Raman spectra were collected using a Renishaw inVia ${ }^{\mathrm{TM}}$ confocal Raman microscope. A laser of $514 \mathrm{~nm}$ was used. X-ray diffraction patterns were recorded in a Bruker D-8 Advance diffractometer. Scanning electron microscopy (SEM) micrographs and energy dispersive (EDX) analyses were obtained using a Hitachi S3500 N. Samples for SEM observation were sputter coated with a gold layer.

Surface analysis by X-ray photoelectron spectroscopy (XPS) [50] and binding energy values (precision $\pm 0.1 \mathrm{eV}$ ) were obtained with a VG-Microtech Multilab 3000. Binding energies were referenced to $\mathrm{C} 1 \mathrm{~s}$ peak $(284.8 \mathrm{eV})$ as internal standard. TEM micrographs were obtained with a high resolution JEOL JEM 2100 microscope. Before TEM observation,

Figure 1. TEM micrographs: a) hybrid GO-NT nanofiller; b) hybrid GO-IL nanofiller. 
GO, GO-NT and GO-IL samples were dispersed in ethanol and ultrasonicated, and a drop was deposited on a 300 mesh copper grid, while thin films (approximately $100 \mathrm{~nm}$ thickness) of PMMA and nanocomposite samples were obtained by ultramicrotomy using a RMC, MT XL model equipment.

Rheological tests were carried out using a AR-G2 rotational rheometer (TA Instruments; USA) of parallel plates at $240^{\circ} \mathrm{C}$, with angular frequency between 0.1 and $200 \mathrm{~s}^{-1}$ under a $1 \%$ constant strain value. The TA Instruments software was used to determine complex viscosity values after the Cox-Merz transformation.

PMMA and nanocomposite materials were processed using a TwinLab $10 \mathrm{~mm}$ co-rotating twin-screw micro-extruder from TwinTech Extrusion Ltd, (U.K.), with a length/diameter $(L / D)$ relationship of 25 .

\section{Results and discussion}

\subsection{Characterization of the nanofillers}

Figure 1 shows the TEM micrographs of hybrid nanofillers GO-NT (Figure 1a) and GO-IL (Figure 1b). While the main effect of the GO-NT blend is a certain disentanglement of carbon nanotubes, GO-IL shows a very relevant modification of GO sheets with the formation of new nanostructures with a rounded morphology and a maximum diameter of around $100 \mathrm{~nm}$.

X-ray diffraction patterns (Figure 2) show the effect of NT and IL on GO interlayer distance. Results confirm the GO-NT is a blend with maximum diffraction peaks characteristic of both nanofillers $\left(2 \theta=11^{\circ}\right.$; graphene plane (001) and $2 \theta=26^{\circ}$; NT (002) plane), with no significant changes in the GO interlayer

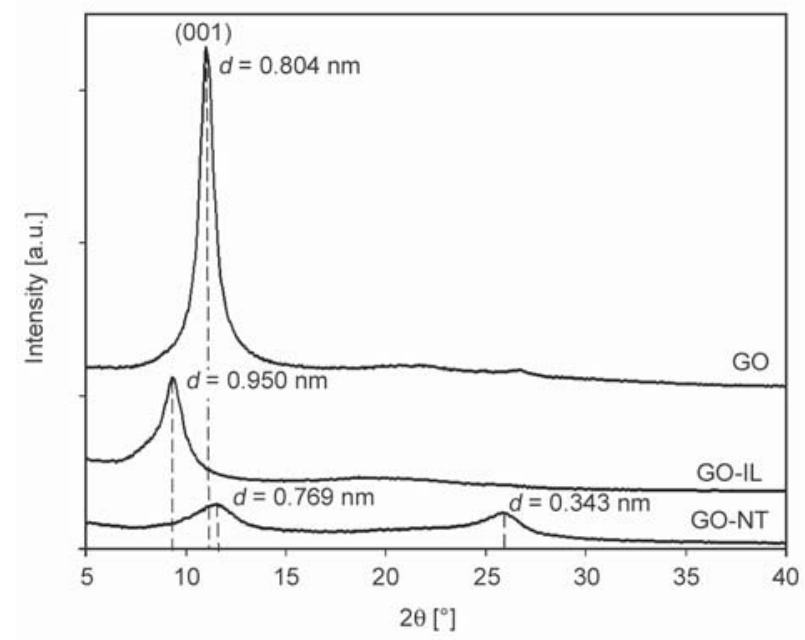

Figure 2. XRD difractograms of GO and hybrid nanofillers GO-NT and GO-IL.

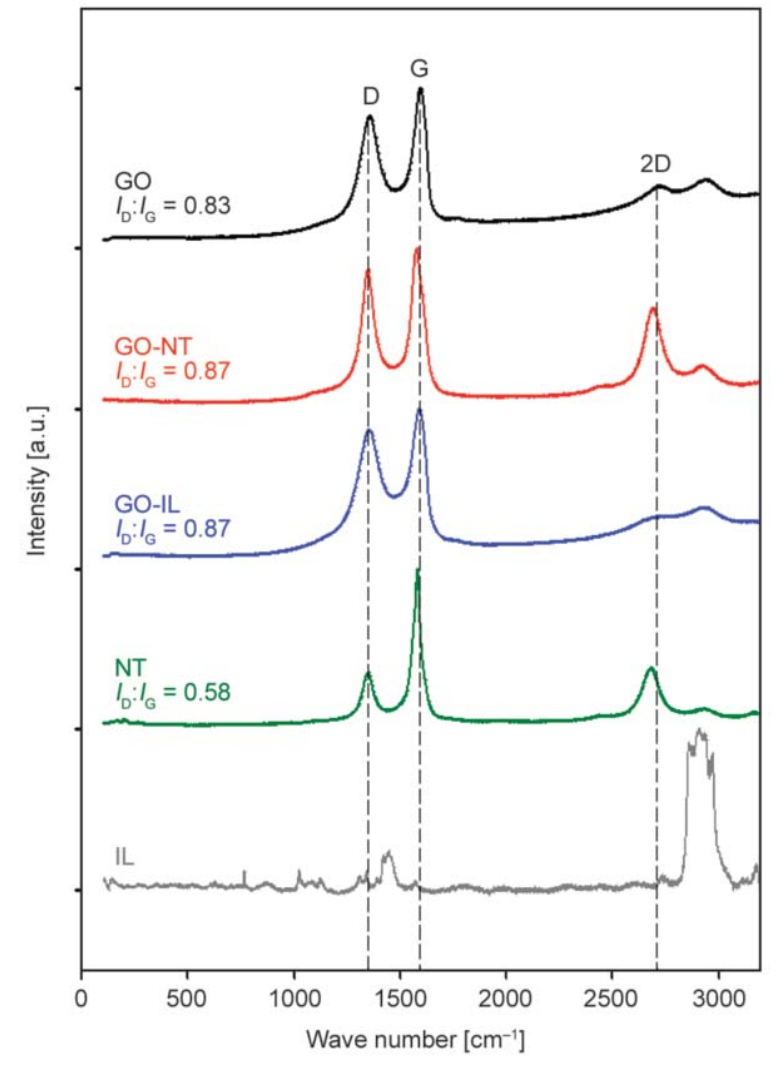

Figure 3. Raman spectra of IL and carbon nanofillers.

distance. In contrast, treatment with IL clearly displaces the GO diffraction peak from $0.80 \mathrm{~nm}$ for unmodified GO, to $0.95 \mathrm{~nm}\left(2 \theta=9.3^{\circ}\right)$ for GO-IL.

Raman spectra (Figure 3) show D, G and 2D bands of GO at $1356.5 ; 1593.6$ and $2725.5 \mathrm{~cm}^{-1}$, respectively. The intensity relationship between $\mathrm{D}$ and $\mathrm{G}$ bands of GO is only very slightly increased after modification by NT or IL. In agreement with TEM and XRD results, the Raman spectrum of GO-NT shows the presence of both nanofillers, while the intense bands characteristic of $\mathrm{C}-\mathrm{H}$ bonds in the Raman spectrum IL are not present in that of GO-IL, thus showing that no significant amount of free IL remains in the hybrid nanofiller.

XPS analysis (Figure 4) shows the characteristic $\mathrm{C} 1 \mathrm{~s}$ $(286.8 \mathrm{eV})$ and the intense $\mathrm{O} 1 \mathrm{~s}(533.9 \mathrm{eV})$ peaks due to the presence of the oxygen-containing functional groups on the surface of GO. The intensity of the $\mathrm{O} 1 \mathrm{~s}$ peak decreases with the addition of NTs. GO-IL shows the same peaks as GO, with the addition of weak N1s $(401.4 \mathrm{eV})$ and $\mathrm{F} 1 \mathrm{~s}(686.0 \mathrm{eV})$ peaks due to the imidazolium cations and the tetrafluoroborate anions present in IL. This confirms the modification of the GO surface by interaction with IL molecules. Thermogravimetric analysis (Figure 5) shows that GO-IL is the most stable nanofiller up to $230^{\circ} \mathrm{C}$. 


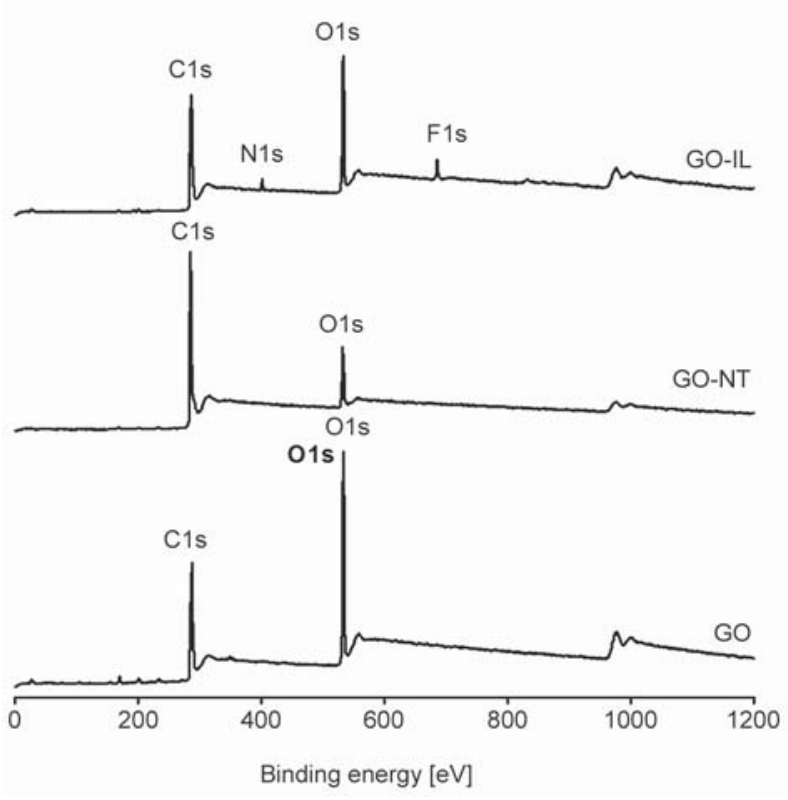

Figure 4. XPS spectra of GO and hybrid nanofillers.

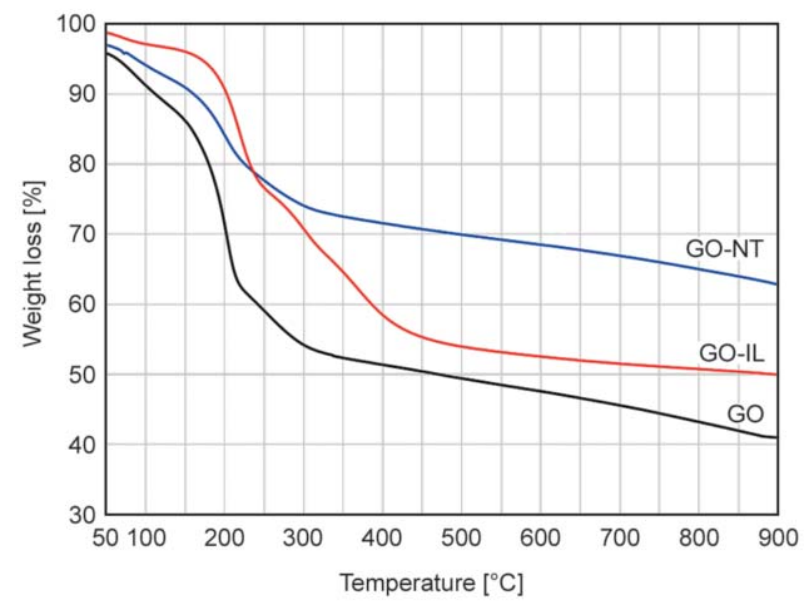

Figure 5. TGA thermograms for GO and hybrid nanofillers.

From this temperature, the highest thermal stability is obtained for GO-NT, while the highest mass loss at all temperatures is found for unmodified GO, where the lack of interaction with NT or IL promotes mass loss due to decomposition of the oxygen-containing functional groups.

The results described above show that hybrid nanofillers are more stable than GO. While GO-NT behaves like a mixture, the IL modifies the morphology, microstructure and composition of GO increasing interlayer spacing and giving rise to the formation of IL-containing nanospheres on GO layers.

\subsection{Micro-extrusion feed rate calibration}

To reach the steady state processing using the twinscrew micro-extruder (Figure 6a), it is necessary to achieve a constant flow rate of material input to the extruder. Since the polymers are going to be fed to
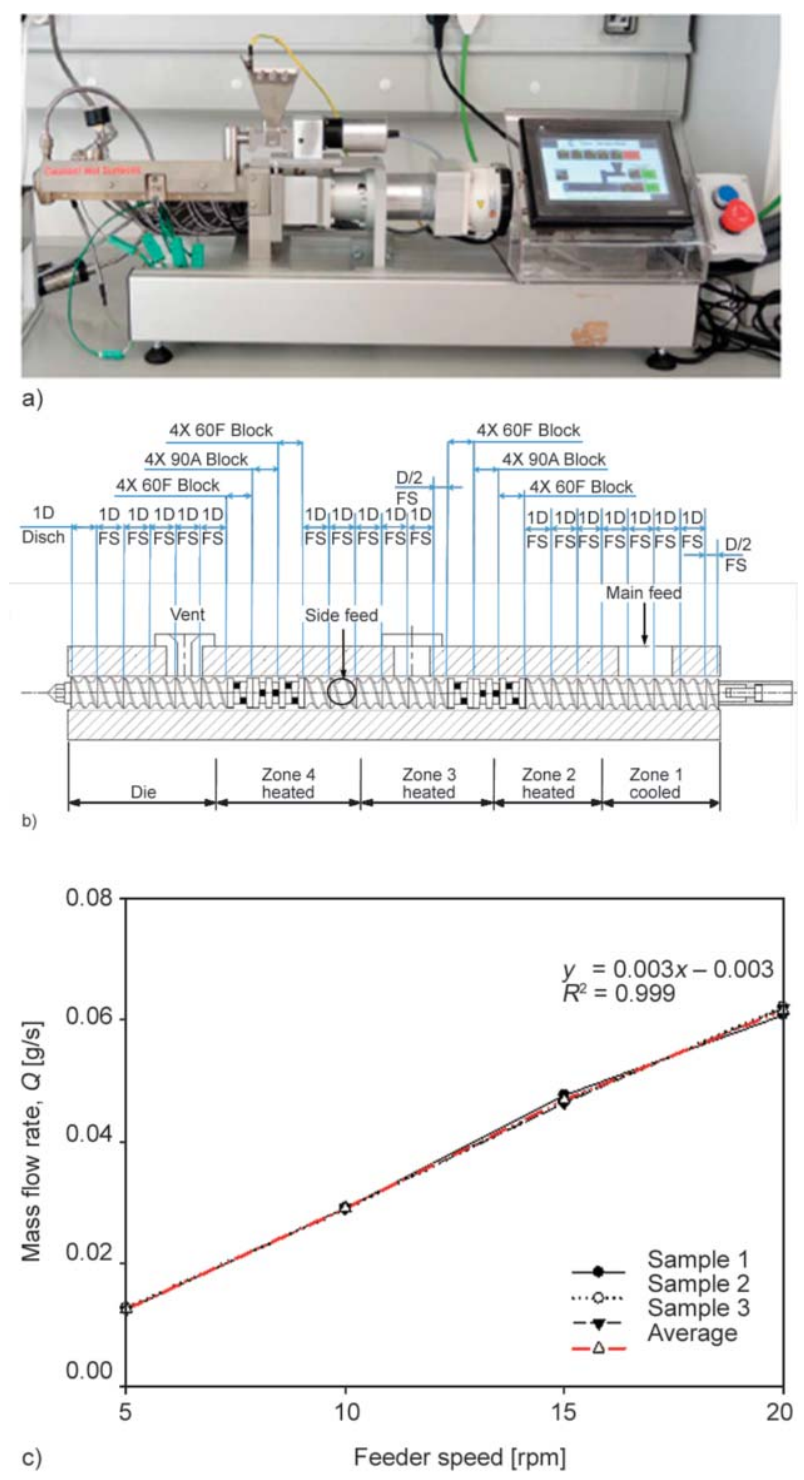

Figure 6. a) Twin-screw micro-extrusion machine; b) screw zones with transport (FS) and mixing (block) elements; c) results of the calibration of mass flow rate with feeder speed.

the extruder from the feeder in powder form, it is necessary to know, for each thermoplastic to be processed, the feed rate provided by the feeder as a function of the feeder screw rotation speed. In order to achieve this, the pellets are grinded under the same conditions, then the polymeric material is placed into the feeder hopper and the feed rate (mass of material per time unit) is measured at different feeder rotation speeds (Figure 6b).

This procedure is then repeated three times with three different samples of each polymer to check if the feeding process fits a linear regression line. Figure $6 \mathrm{c}$ represents experimental results of feed rate versus feeder rotation speed and the regression line, equation and the squared correlation coefficient. 


\subsection{Micro-extrusion temperature profiles and processing window}

The processing window [39] of pure PMMA was established for two temperature profiles, which will be called high and low, respectively (Figure 7a). Once both temperature profiles have been validated, the micro-extruder conditions for which the extruded material shows degradation (flows too slowly, or remains unprocessed and raw) are identified.

For each temperature profile, two values of $S M E$ (high and low), for which the material is properly processed, are selected.

The $S M E$ values $[\mathrm{kJ} / \mathrm{kg}]$ are determined according to Equation (1):

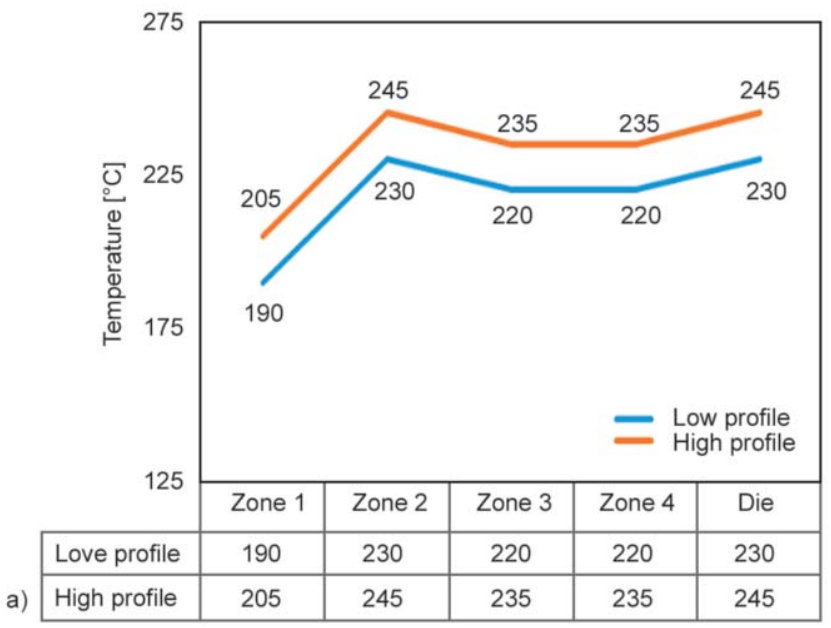

$S M E=\frac{2 \pi \cdot \tau \cdot N}{Q}$

where $N$ is the screw speed [rpm] and $\tau$ is the torque $[\mathrm{Nm}]$, while $Q$ is the mass flow rate $[\mathrm{kg} /$ hour $]$ of the extruded material $[41,44]$.

Figure $7 \mathrm{~b}$ shows the processing window, with high $(1800 \mathrm{~kJ} / \mathrm{kg})$ and low $(720 \mathrm{~kJ} / \mathrm{kg}) S M E$ values for both temperature profiles.

For the low temperature profile, PMMA is adequately extruded under the whole range of processing conditions, except for a low extruder speed of $50 \mathrm{rpm}$ and a high feeder speed of $20 \mathrm{rpm}$ (Table 1). In this case, the conditions are above the security level of

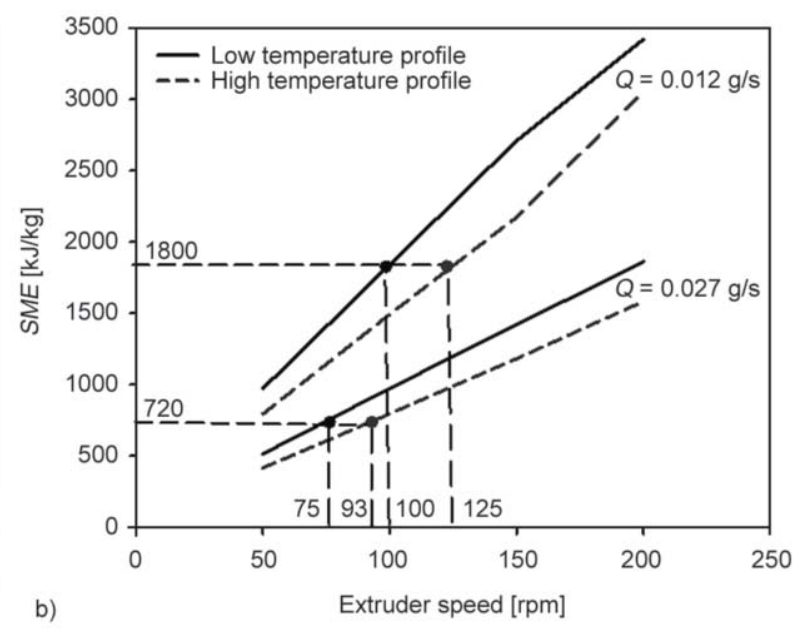

Figure 7. a) High and low temperature profiles at the different screw zones; b) SME values for both temperature profiles $(Q-$ mass flow rate).

Table 1. SME values obtained for PMMA under different extrusion conditions.

\begin{tabular}{|c|c|c|c|c|c|c|}
\hline \multirow{3}{*}{$\begin{array}{c}\text { Feeder speed } \\
\text { [rpm] }\end{array}$} & \multirow{3}{*}{$\begin{array}{c}\text { Mass flow rate } \\
\text { [kg/hour] }\end{array}$} & \multirow{3}{*}{$\begin{array}{c}\text { Extruder speed } \\
\text { [rpm] }\end{array}$} & \multicolumn{2}{|c|}{$\begin{array}{l}\text { Torque } \\
{[\mathbf{N} \cdot \mathbf{m}]}\end{array}$} & \multicolumn{2}{|c|}{$\begin{array}{c}S M E \\
{[\mathrm{~kJ} / \mathrm{kg}]}\end{array}$} \\
\hline & & & \multicolumn{4}{|c|}{ Temperature profile } \\
\hline & & & Low & High & Low & High \\
\hline \multirow{4}{*}{5} & \multirow{4}{*}{0.043} & 50 & 2.23 & 1.82 & 973.0 & 794.1 \\
\hline & & 100 & 2.11 & 1.71 & 1841.3 & 1492.3 \\
\hline & & 150 & 2.07 & 1.66 & 2709.6 & 2172.9 \\
\hline & & 200 & 1.96 & 1.75 & 3420.8 & 3054.3 \\
\hline \multirow{4}{*}{10} & \multirow{4}{*}{0.097} & 50 & 2.65 & 2.14 & 513.9 & 415.0 \\
\hline & & 100 & 2.51 & 2.05 & 973.5 & 795.1 \\
\hline & & 150 & 2.44 & 2.03 & 1419.5 & 1181.0 \\
\hline & & 200 & 2.40 & 2.04 & 1861.7 & 1582.4 \\
\hline \multirow{4}{*}{15} & \multirow{4}{*}{0.151} & 50 & 3.24 & 2.52 & 403.9 & 314.2 \\
\hline & & 100 & 2.91 & 2.39 & 725.6 & 595.9 \\
\hline & & 150 & 2.75 & 2.27 & 1028.5 & 849.0 \\
\hline & & 200 & 2.57 & 2.22 & 1281.6 & 1107.0 \\
\hline \multirow{4}{*}{20} & \multirow{4}{*}{0.205} & 50 & - & 2.81 & - & 258.1 \\
\hline & & 100 & 3.16 & 2.57 & 580.6 & 472.2 \\
\hline & & 150 & 2.96 & 2.36 & 815.7 & 650.4 \\
\hline & & 200 & 2.77 & 2.25 & 1017.8 & 826.7 \\
\hline
\end{tabular}


Table 2. SME values obtained for PMMA nanocomposites under different extrusion conditions.

\begin{tabular}{|c|c|c|c|c|}
\hline \multicolumn{5}{|c|}{ PMMA+GO } \\
\hline $\begin{array}{c}\text { Feeder } \\
\text { speed } \\
{[\mathrm{rpm}]}\end{array}$ & $\begin{array}{c}\text { Temperature } \\
\text { profile }\end{array}$ & $\begin{array}{c}\text { Extruder } \\
\text { speed } \\
\text { [rpm] }\end{array}$ & $\begin{array}{l}\text { Torque } \\
{[\mathbf{N} \cdot \mathbf{m}]}\end{array}$ & $\begin{array}{c}S M E \\
{[\mathrm{~kJ} / \mathrm{kg}]}\end{array}$ \\
\hline \multirow{4}{*}{7} & \multirow{2}{*}{ High } & 149 & 2.10 & 1820 \\
\hline & & 150 & 2.08 & 1815 \\
\hline & \multirow{2}{*}{ Low } & 120 & 2.60 & 1815 \\
\hline & & 132 & 2.35 & 1804 \\
\hline \multirow{4}{*}{10} & \multirow{2}{*}{ High } & 85 & 2.20 & 725 \\
\hline & & 87 & 2.16 & 729 \\
\hline & \multirow{2}{*}{ Low } & 61 & 3.08 & 728 \\
\hline & & 62 & 3.01 & 721 \\
\hline \multicolumn{5}{|c|}{ PMMA+GO-NT } \\
\hline \multirow{4}{*}{7} & \multirow{2}{*}{ High } & 172 & 1.82 & 1821 \\
\hline & & 160 & 1.95 & 1815 \\
\hline & \multirow{2}{*}{ Low } & 120 & 2.60 & 1815 \\
\hline & & 120 & 2.59 & 1808 \\
\hline \multirow{4}{*}{10} & \multirow{2}{*}{ High } & 87 & 2.20 & 729 \\
\hline & & 91 & 2.05 & 723 \\
\hline & \multirow{2}{*}{ Low } & 64 & 2.92 & 725 \\
\hline & & 63 & 2.05 & 723 \\
\hline \multicolumn{5}{|c|}{ PMMA+GO-IL } \\
\hline \multirow{4}{*}{7} & \multirow{2}{*}{ High } & 187 & 1.66 & 1806 \\
\hline & & 171 & 1.81 & 1800 \\
\hline & \multirow{2}{*}{ Low } & 135 & 2.30 & 1806 \\
\hline & & 132 & 2.35 & 1804 \\
\hline \multirow{4}{*}{10} & \multirow{2}{*}{ High } & 98 & 1.92 & 729 \\
\hline & & 85 & 2.20 & 725 \\
\hline & \multirow{2}{*}{ Low } & 69 & 2.70 & 722 \\
\hline & & 64 & 2.90 & 720 \\
\hline
\end{tabular}

the microextruder and it stops automatically, so $S M E$ could not be determined.

Under the high temperature profile conditions, PMMA shows good processability. As it can be observed in Table 1, for a constant mass flow rate, $S M E$ values decrease with temperature increase. This behaviour could be related to the reduction in the viscosity of the melt at high temperature, as will be discussed in Section 3.5.

Table 2 shows that the experimental SME values for nanocomposite materials are close to the selected high $(1800 \mathrm{~kJ} / \mathrm{kg})$ and low $(720 \mathrm{~kJ} / \mathrm{kg})$ values.

\subsection{Dynamic-mechanical properties of PMMA and nanocomposites}

Glass transition temperature values determined from DMA analysis (Table 3), are very close for neat PMMA and for the nanocomposites, for the different temperature profiles and $S M E$ values. This shows that
PMMA chain mobility is not significantly altered either by the addition of the nanofillers or by the processing conditions studied here.

The storage modulus $\left(E^{\prime}\right)$ of the nanocomposites processed at high temperature and high $S M E$ is displaced to lower values with respect to PMMA. The opposite effect is observed for nanocomposites processed at high temperature and low SME which, in all cases, present higher storage modulus values than PMMA.

PMMA and PMMA+GO show similar storage modulus values, with maximum variations (under different extrusion conditions) lower than $10 \%$.

All nanocomposites show the highest $E^{\prime}$ values for high temperature and low $S M E$ conditions. Processing under higher temperature would decrease polymer viscosity and improve the dispersion of the nanofillers in the PMMA matrix of the extruded composite material. The most significant influence of extrusion conditions is found for hybrid nanocomposites PMMA+GO-NT and PMMA+GO-IL, which show maximum storage modulus differences of 19.9 and $17.8 \%$, respectively

This results show that the selection of processing parameters is more relevant for hybrid nanocomposites. In all cases, variations of loss modulus of nanocomposites follow the same trend as that described for storage modulus and finally, no variation is found for the loss factor $(\tan \delta)$ for the whole set of experimental conditions and materials.

\subsection{Rheological behaviour of PMMA and nanocomposites}

Complex viscosity values after Cox-Merz transformation are represented in Figure 8. Nanocomposites processed under the high temperature profile with high $S M E$ (Figure 8a) show lower viscosity values than those processed with low SME (Figure 8b). This viscosity decrease is an effect of nanofiller dispersion, as it can not be attributed to polymer chains degradation or fracture, as PMMA shows the same viscosity for both $S M E$ values.

A shear thinning effect takes place as shear rate increases, as a result of the alignment of polymer chains. Finally, at maximum shear rate, all samples show the same viscosity as the neat polymer, as the rheological behaviour depends on the matrix rather than on the additives.

Under low shear rates, the added nanofillers increase the viscosity of the polymer. Under these conditions, 
Table 3. DMA results for all materials and processing conditions (average values of at least 6 tests, with standard deviation lower than $10 \%$ ).

\begin{tabular}{|c|c|c|c|c|c|c|c|c|c|c|c|c|}
\hline \multicolumn{13}{|c|}{ High temperature profile } \\
\hline \multirow[b]{2}{*}{ Material } & \multicolumn{6}{|c|}{ High SME } & \multicolumn{6}{|c|}{ Low $S M E$} \\
\hline & $\begin{array}{c}E_{\text {onset }}^{\prime} \\
{[\mathrm{MPa}]}\end{array}$ & $\begin{array}{c}T_{\mathrm{g}} \\
{\left[{ }^{\circ} \mathbf{C}\right)}\end{array}$ & $\begin{array}{c}E_{\max }^{\prime \prime} \\
{[\mathrm{MPa}]}\end{array}$ & $\begin{array}{c}T_{\mathrm{g}} \\
{\left[{ }^{\circ} \mathbf{C}\right)}\end{array}$ & $\tan \delta$ & $\begin{array}{c}T_{\mathrm{g}} \\
{\left[{ }^{\circ} \mathbf{C}\right)}\end{array}$ & $\begin{array}{c}E_{\text {onset }}^{\prime} \\
\text { [MPa] }\end{array}$ & $\begin{array}{c}T_{\mathrm{g}} \\
{\left[{ }^{\circ} \mathbf{C}\right)}\end{array}$ & $\begin{array}{c}E_{\max }^{\prime \prime} \\
{[\mathrm{MPa}]}\end{array}$ & $\begin{array}{c}T_{\mathrm{g}} \\
{\left[{ }^{\circ} \mathbf{C}\right)}\end{array}$ & $\tan \delta$ & $\begin{array}{c}T_{\mathrm{g}} \\
{\left[{ }^{\circ} \mathbf{C}\right)}\end{array}$ \\
\hline PMMA & 3087 & 119.4 & 241.3 & 119.2 & 1.6 & 138.0 & 2958 & 118.8 & 241.7 & 119.0 & 1.6 & 137.0 \\
\hline $\mathrm{PMMA}+\mathrm{GO}$ & 2956 & 119.0 & 233.3 & 118.4 & 1.6 & 137.0 & 3222 & 119.1 & 250.4 & 118.7 & 1.7 & 138.2 \\
\hline $\mathrm{PMMA}+\mathrm{GO}-\mathrm{NT}$ & 2869 & 119.5 & 240.2 & 119.4 & 1.6 & 138.1 & 3266 & 119.2 & 252.1 & 119.2 & 1.6 & 137.2 \\
\hline PMMA+GO-IL & 2558 & 119.3 & 236.8 & 119.2 & 1.7 & 137.5 & 3112 & 118.7 & 245.2 & 118.1 & 1.7 & 136.7 \\
\hline \multicolumn{13}{|c|}{ Low temperature profile } \\
\hline \multirow[b]{2}{*}{ Material } & \multicolumn{6}{|c|}{ High SME } & \multicolumn{6}{|c|}{ Low $S M E$} \\
\hline & $\begin{array}{c}E_{\text {onset }}^{\prime} \\
{[\mathrm{MPa}]}\end{array}$ & $\begin{array}{c}\boldsymbol{T}_{\mathbf{g}} \\
{\left[{ }^{\circ} \mathbf{C}\right)}\end{array}$ & $\begin{array}{c}E_{\max }^{\prime \prime} \\
{[\mathrm{MPa}]}\end{array}$ & $\begin{array}{c}T_{\mathbf{g}} \\
{\left[{ }^{\circ} \mathbf{C}\right)}\end{array}$ & $\tan \delta$ & $\begin{array}{c}T_{\mathrm{g}} \\
{\left[^{\circ} \mathbf{C}\right)}\end{array}$ & $\begin{array}{c}E_{\text {onset }}^{\prime} \\
{[\mathrm{MPa}]}\end{array}$ & $\begin{array}{c}T_{\mathrm{g}} \\
{\left[{ }^{\circ} \mathbf{C}\right)}\end{array}$ & $\begin{array}{c}E_{\max }^{\prime \prime} \\
{[\mathrm{MPa}]}\end{array}$ & $\begin{array}{c}T_{\mathbf{g}} \\
{\left[{ }^{\circ} \mathbf{C}\right)}\end{array}$ & $\tan \delta$ & $\begin{array}{c}T_{\mathbf{g}} \\
{\left[{ }^{\circ} \mathbf{C}\right)}\end{array}$ \\
\hline PMMA & 3138 & 119.3 & 240.8 & 119.3 & 1.6 & 137.6 & 3162 & 118.1 & 235.8 & 118.5 & 1.7 & 137.1 \\
\hline $\mathrm{PMMA}+\mathrm{GO}$ & 3199 & 119.5 & 255.8 & 119.7 & 1.7 & 137.5 & 3011 & 119.2 & 236.1 & 119.1 & 1.7 & 137.2 \\
\hline PMMA+GO-NT & 3163 & 120.0 & 241.4 & 120.7 & 1.6 & 137.2 & 2617 & 119.6 & 229.7 & 119.8 & 1.7 & 137.5 \\
\hline PMMA+GO-IL & 2953 & 119.6 & 230.0 & 120.3 & 1.7 & 137.7 & 2836 & 119.2 & 233.5 & 119.2 & 1.7 & 137.7 \\
\hline
\end{tabular}

$E^{\prime}$ - storage modulus;

$E^{\prime \prime}$ - loss modulus;

$\tan \delta$ (dissipation factor or loss coefficient) $-E^{\prime \prime} / E^{\prime}$;

$T_{\mathrm{g}}$ - glass transition temperature.

the viscosity values depend on the dispersion of the nanofillers in the polymer matrix $[49,51]$.

A high $S M E$ value slightly improves the dispersibility of GO-NT. For both $S M E$ conditions, a better dispersion and lower viscosity is found for GO-IL.

After the properties reported in sections 3.4 and 3.5, nanocomposites processed under high $S M E$ were selected for further microstructural characterization, which shall be discussed in the following section.

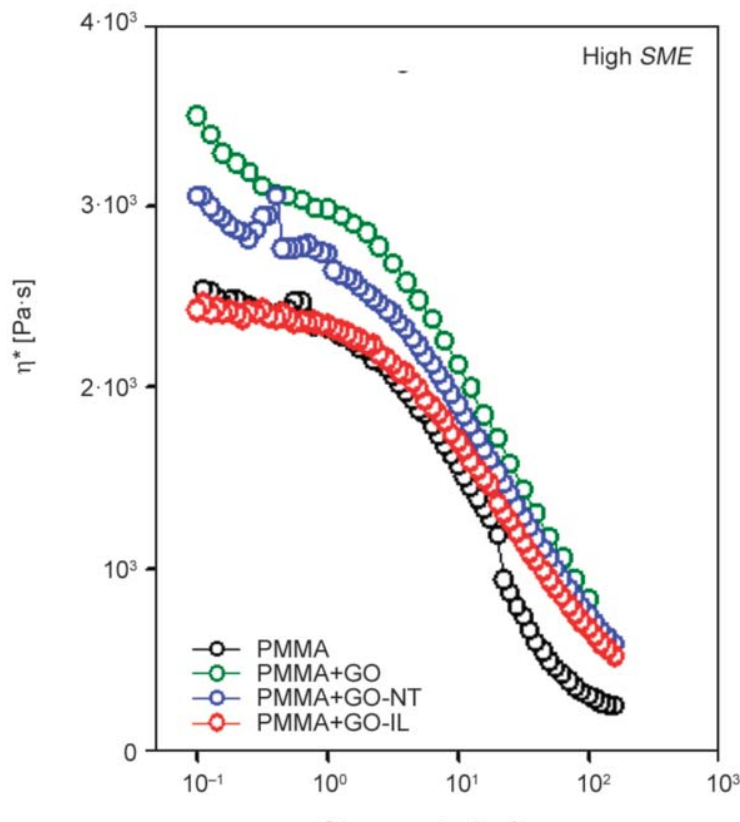

a)

Shear rate $\left[\mathbf{s}^{-1}\right]$

\subsection{Microstructural characterization of the nanocomposites.}

Micro-extruded materials were studied, in the first place, by TEM microscopy. Figure 9a shows the presence of very large GO agglomerates in $\mathrm{PMMA}+\mathrm{GO}$ processed with high $S M E$. The size of the agglomerates is somewhat reduced for low SME. However, in both cases, large areas of the PMMA matrix remain free from GO. Addition of NT produces a more

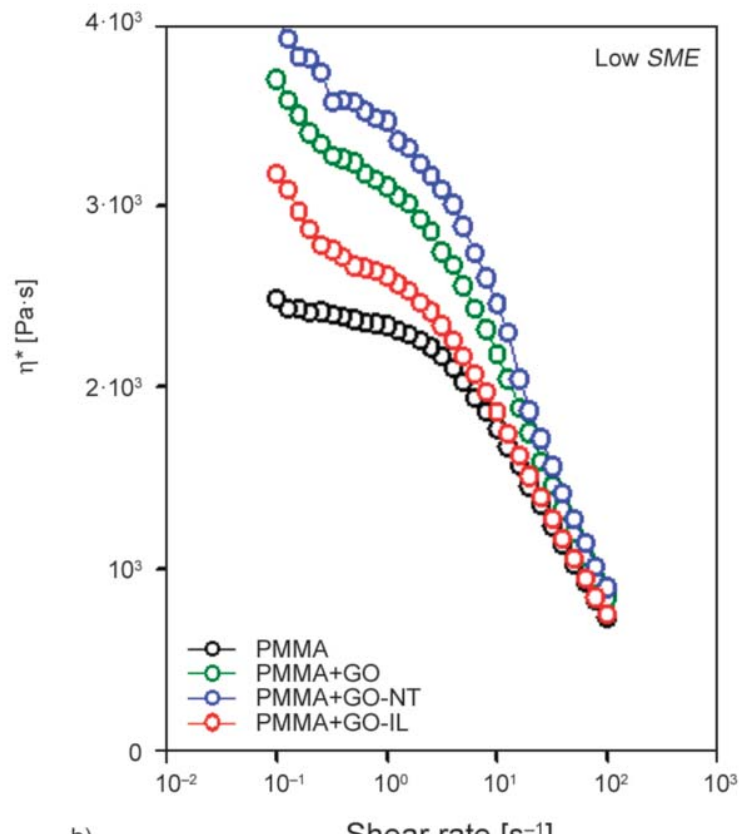

b)

Shear rate $\left[\mathrm{s}^{-1}\right]$

Figure 8. Complex viscosity vs shear rate for PMMA and nanocomposites processed at a) high and b) low $S M E$. 


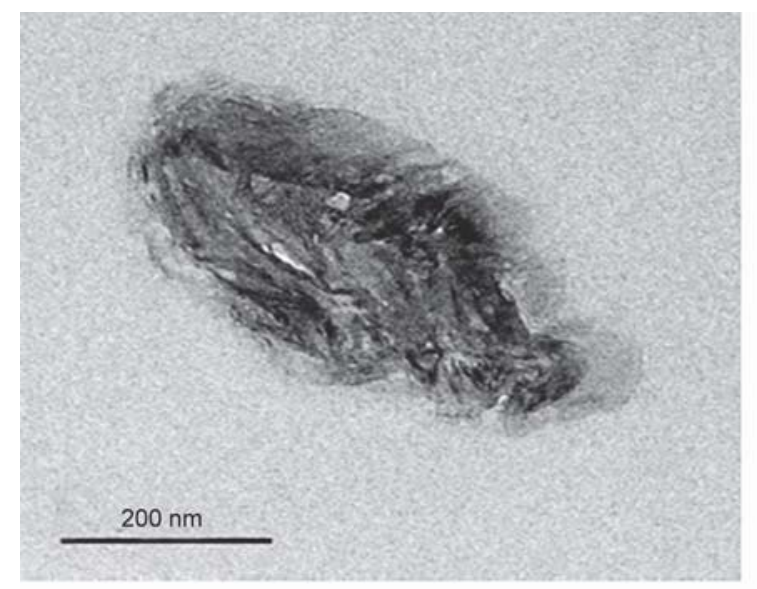

a)

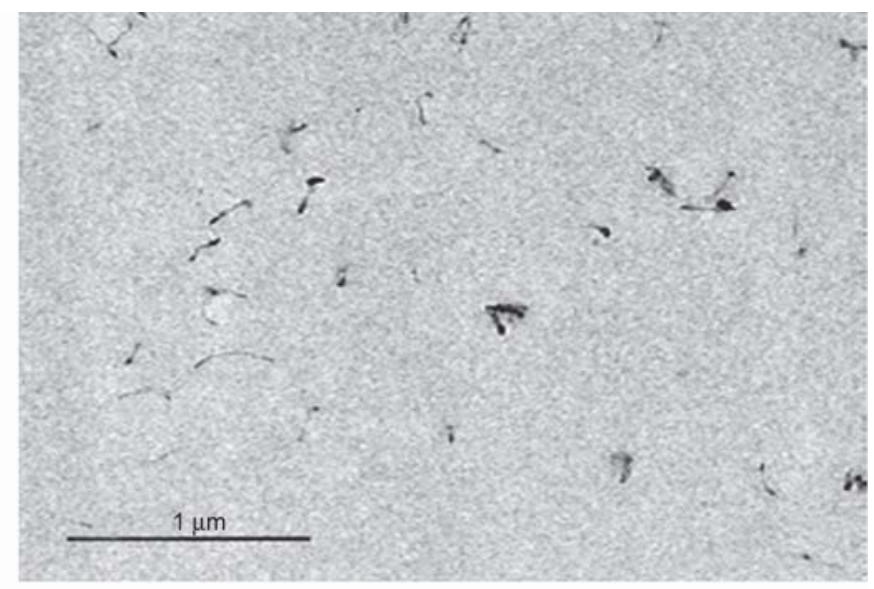

b)

Figure 9. TEM micrographs of: a) PMMA+GO; b) PMMA+GO-NT.

homogeneous distribution of the GO-NT hybrid nanofiller in the PMMA matrix (Figure 9b), both at high and low SME.

After treatment with IL, IL-containing nanospheres present in GO-IL (Figure 1b), are also found into the PMMA matrix of PMMA+GO-IL (Figure 10a). Higher magnification (Figure 10b) shows the fluorine-containing (see EDX spectrum) nanospheres associated with GO layers.

SEM micrographs of the cryofracture surfaces show the expected fragile behaviour of PMMA (Figure 11a). Although SEM microscopy is not able to detect GO nanofillers, fluorine element map of PMMA+GO-IL (Figure 11b) confirms the homogeneous distribution of fluorine from the tetrafluoroborate anion of the IL, without large agglomerates or large regions free from fluorine.

These results confirm the modification of GO by interaction with IL, and the good dispersibility of the hybrid GO-IL nanofiller with respect to unmodified GO (Figure 9a), and are in agreement with the lower viscosity values obtained for PMMA+GO-IL.

$\mathrm{X}$-ray diffractograms of neat PMMA (Figure 12) is in agreement with its amorphous nature, showing an intense broad peak at $2 \theta=13 \cdot 3^{\circ}$. However, two weak sharp peaks at $2 \theta=26.4^{\circ}$ and $2 \theta=29.2^{\circ}$ show the presence of some ordered crystalline domains. These peaks are very weak or disappear in $\mathrm{PMMA}+\mathrm{GO}$ and $\mathrm{PMMA}+\mathrm{GO}-\mathrm{NT}$ nanocomposites. In contrast, $\mathrm{PMMA}+\mathrm{GO}-\mathrm{IL}$ shows a more intense diffraction at

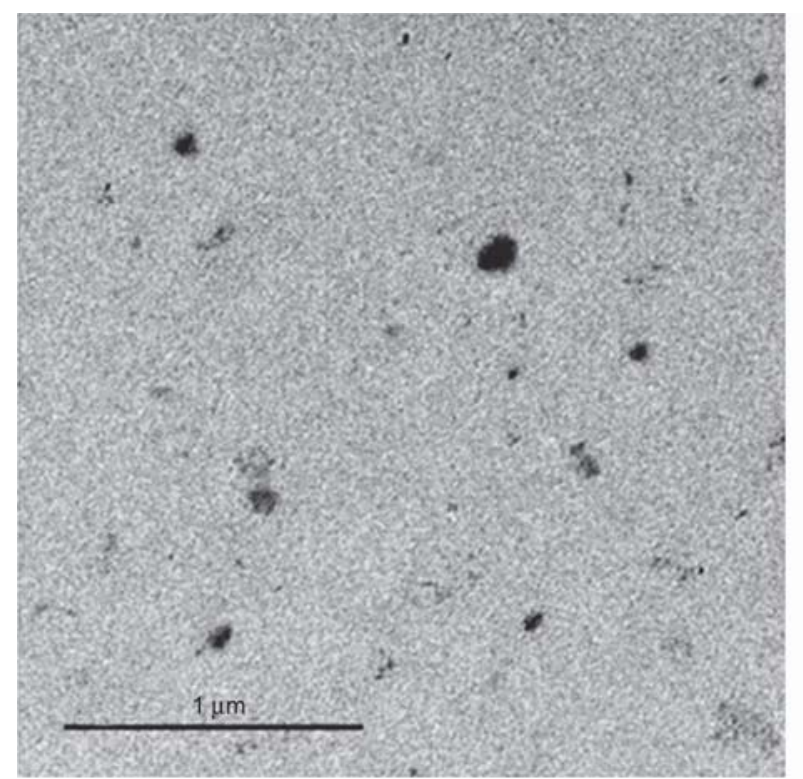

a)

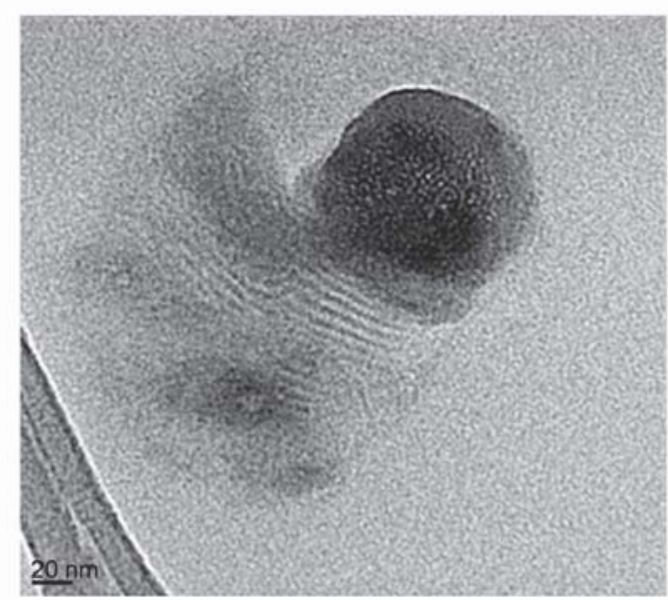

b)

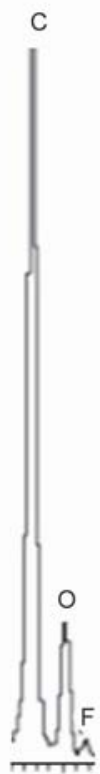

Figure 10. a) TEM micrographs of PMM+GO-IL; b) magnifications showing GO-IL nanospheres and EDX spectrum. 


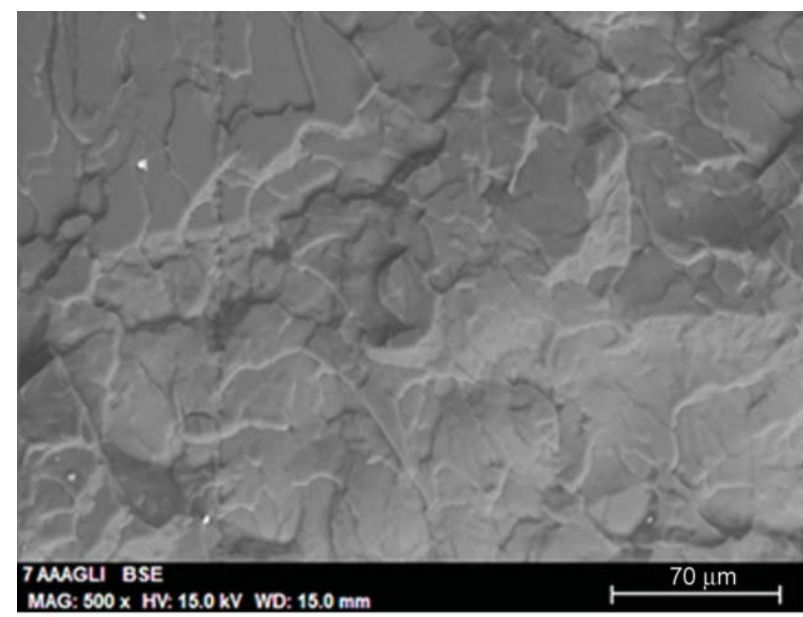

a)

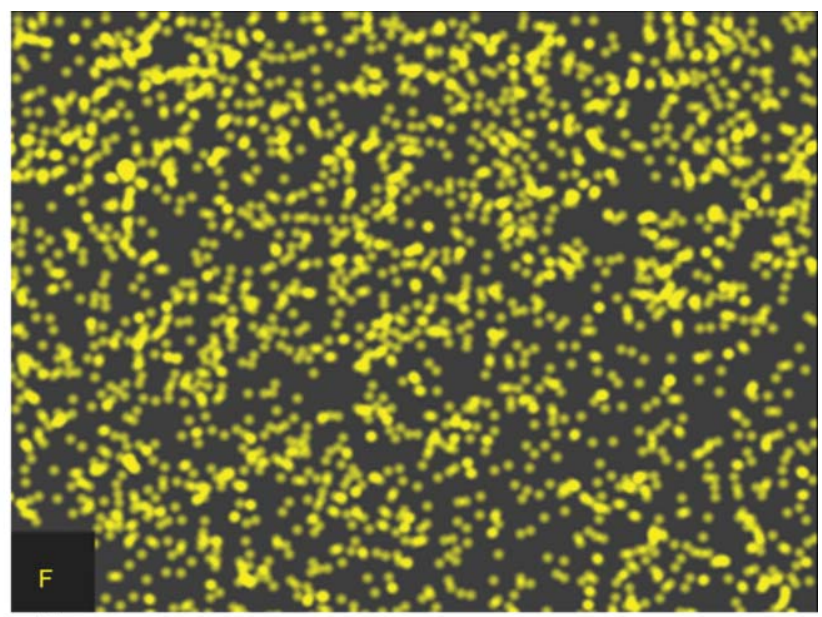

b)

Figure 11. PMMA+GO-IL: a) SEM micrograph of the cryofracture surface and b) fluorine element map.

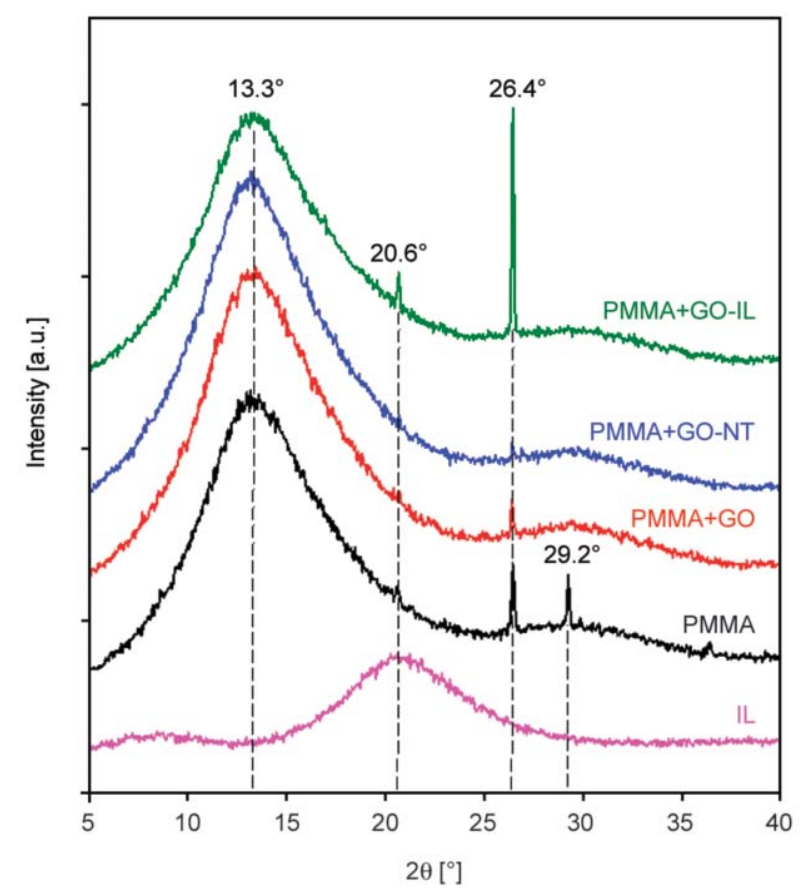

Figure 12. XRD diffractograms of IL, PMMA and nanocomposites.

$2 \theta=26.4^{\circ}$, together with the new peak at $2 \theta=20.6^{\circ}$, which could be assigned to IL, as it corresponds to the $2 \theta$ value of the broad diffraction found for neat IL. The less ordered material is the nanocomposite containing the mixture of graphene oxide and carbon nanotubes (PMMA+GO-NT), which shows no sharp diffraction peaks.

\section{Conclusions}

Hybrid nanofillers by mixing graphene oxide with multiwalled carbon nanotubes or treatment with ionic liquid have been obtained and characterized. Both hybrid nanofillers show higher thermal stability than unmodified graphene oxide. Modification with ionic liquid changes the morphology, structure and surface composition of graphene oxide.

The twin-screw micro-extrusion of PMMA and nanocomposites with low $0.5 \mathrm{wt} \%$ concentration of graphene oxide or hybrid nanofillers has been studied under different processing parameters such as feed rate, extruder speed, temperature profiles and specific mechanical energy.

Hybrid nanofillers decrease the size of aggregates and improve the dispersion of graphene oxide in the polymer matrix, without altering the glass transition temperature of the polymer.

Processing parameters such as temperature profile and specific mechanical energy show a stronger influence on the dynamic mechanical properties and rheological behaviour of hybrid nanocomposites, than on the neat polymer.

The lowest viscosity is found for the polymer containing graphene oxide modified by ionic liquid, which is attributed to the good dispersion of the modified nanofiller.

The results described here show the relevance of modification of the nanofillers and selection of process parameters on the final properties of extruded nanocomposites, even for a low concentration of added nanofillers.

The combination of microstructure and properties found for the nanocomposite containing graphene oxide modified by ionic liquid make it a suitable candidate for in-progress current studies on mechanical and tribological behaviour of final parts melt processed by extrusion and injection molding. 


\section{Acknowledgements}

The authors gratefully acknowledge the financial support of Ministerio de Economía y Competitividad and Agencia Estatal de Investigación (MINECO and AEI, Spain), EU FEDER (MAT2017-85130-P) and the Fundación Séneca, Agencia de Ciencia y Tecnología de la Región de Murcia ('Ayuda a las Unidades y Grupos de Excelencia Científica de la Región de Murcia'; Grant \# 19877/GERM/1

\section{References}

[1] Spitalsky Z., Tasis D., Papagelis K., Galiotis C.: Carbon nanotube-polymer composites: Chemistry, processing, mechanical and electrical properties. Progress in Polymer Science, 35, 357-401 (2010).

https://doi.org/10.1016/j.progpolymsci.2009.09.003

[2] Grady B. P.: Effects of carbon nanotubes on polymer physics. Journal of Polymer Science B: Polymer Physics, 50, 591-623 (2012).

https://doi.org/10.1002/polb.23052

[3] Szeluga U., Kumanek B., Trzebicka B.: Synergy in hybrid polymer/nanocarbon composites. A review. Composites Part A: Applied Science and Manufacturing, 73, 204-231 (2015).

https://doi.org/10.1016/j.compositesa.2015.02.021

[4] Greil P.: Perspectives of nano-carbon based engineering materials. Advanced Engineering Materials, 17, 124137 (2015).

https://doi.org/10.1002/adem.201400110

[5] Mittal G., Dhand V., Rhee K. Y., Park S-J., Lee W. R.: A review on carbon nanotubes and graphene as fillers in reinforced polymer nanocomposites. Journal of Industrial and Engineering Chemistry, 21, 11-25 (2015). https://doi.org/10.1016/j.jiec.2014.03.022

[6] Chen W-J., Zhu Y-Z., Wang S-X., Pei W-F., Jiang Y.: Effects of carbon nanofillers on enhancement of polymer composites. Journal of Applied Physics, 112, 074302/1-074302/4 (2012).

https://doi.org/10.1063/1.4755806

[7] Idumah C. I., Hassan A.: Emerging trends in graphene carbon based polymer nanocomposites and applications. Reviews in Chemical Engineering, 32, 223-264 (2016).

https://doi.org/10.1515/revce-2015-0038

[8] Jabeen S., Kausar A., Muhammad B., Gul S., Farooq M.: A review on polymeric nanocomposites of nanodiamond, carbon nanotube, and nanobifiller: Structure, preparation and properties. Polymer-Plastics Technology and Engineering, 54, 1379-1409 (2015). https://doi.org/10.1080/03602559.2015.1021489

[9] Stankovich S., Dikin D. A., Dommett G. H. B., Kohlaas K. M., Zimney E. J., Stach E. A., Piner R. D., Nguyen S. T., Ruolff R. S.: Graphene-based composite materials. Nature, 442, 282-286 (2006).

https://doi.org/10.1038/nature04969
[10] Papageorgiou D. G., Kinloch I. A., Young R. J.: Mechanical properties of graphene and graphene-based nanocomposites. Progress in Materials Science, 90, 75127 (2017). https://doi.org/10.1016/j.pmatsci.2017.07.004

[11] Punetha V. D., Rana S., Yoo H. J., Chaurasia A., McLeskey J. T., Ramasamy M. S., Sahoo N. G., Cho J. W.: Functionalization of carbon nanomaterials for advanced polymer nanocomposites: A comparison study between CNT and graphene. Progress in Polymer Science, 67, 1-47 (2017). https://doi.org/10.1016/j.progpolymsci.2016.12.010

[12] Du J., Cheng H-M.: The fabrication, properties, and uses of graphene/polymer composites. Macromolecular Chemistry and Physics, 213, 1060-1077 (2012). https://doi.org/10.1002/macp.201200029

[13] Ahmad H., Fan M. Z. Hui D.: Graphene oxide incorporated functional materials: A review. Composites Part B: Engineering, 145, 270-280 (2018). https://doi.org/10.1016/j.compositesb.2018.02.006

[14] Kuilla T., Bhadra S., Yao D., Kim N. H., Bose S., Lee J. $\mathrm{H}$.: Recent advances in graphene based polymer composites. Progress in Polymer Science, 35, 1350-1375 (2010).

https://doi.org/10.1016/j.progpolymsci.2010.07.005

[15] Verdejo R., Bernal M. M., Romasanta L. J., LopezManchado M. A.: Graphene filled polymer nanocomposites. Journal of Materials Chemistry, 21, 3301-3310 (2011). https://doi.org/10.1039/C0JM02708A

[16] Huang X., Qi X., Boey F., Zhang H.: Graphene-based composites. Chemical Society Reviews, 41, 666-686 (2012). https://doi.org/10.1039/C1CS15078B

[17] Mittal V., Chaudhry A. U.: Polymer - graphene nanocomposites: Effect of polymer matrix and filler amount on properties. Macromolecular Materials and Engineering, 300, 510-521 (2015). https://doi.org/10.1002/mame.201400392

[18] Xu Z., Gao C.: In situ polymerization approach to graphene-reinforced nylon- 6 composites. Macromolecules, 43, 6716-6723 (2010). https://doi.org/10.1021/ma1009337

[19] Kim H., Kobayashi S., AbdurRahim M., Zhang M. J., Khusainova A., Hillmayer M. A., Abdala A. A., Macosko C. W.: Graphene/polyethylene nanocomposites: Effect of polyethylene functionalization and blending methods. Polymer, 52, 1837-1846 (2011). https://doi.org/10.1016/j.polymer.2011.02.017

[20] Vallés C., Kinloch I. A., Young R. J., Wilson N. R., Rourke J. P.: Graphene oxide and base-washed graphene oxide as reinforcements in PMMA nanocomposites. Composites Science and Technology, 88, 158-164 (2013). https://doi.org/10.1016/j.compscitech.2013.08.030 
[21] Istrate O. M., Paton K. R., Khan U., O’Neill A., Bell A. P., Coleman J. N.: Reinforcement in melt-processed polymer-graphene composites at extremely low graphene loading level. Carbon, 78, 243-249 (2014). https://doi.org/10.1016/j.carbon.2014.06.077

[22] Mittal V.: Functional polymer nanocomposites with graphene: A review. Macromolecular Materials and Engineering, 299, 906-931 (2014). https://doi.org/10.1002/mame.201300394

[23] Yang Y-K., He C-E., Peng R-G., Baji A., Du X. S., Huang Y-L., Xie X-L., Mai Y-W.: Non-covalently modified graphene sheets by imidazolium ionic liquids for multifunctional polymer nanocomposites. Journal of Materials Chemistry, 22, 5666-5675 (2012). https://doi.org/10.1039/C2JM16006D

[24] Carrión F. J., Espejo C., Sanes J., Bermúdez M. D.: Single-walled carbon nanotubes modified by ionic liquid as antiwear additives of thermoplastics. Composites Science and Technology, 70, 2160-2167 (2010). https://doi.org/10.1016/j.compscitech.2010.08.018

[25] Sanes J., Saurin N., Carrión F. J., Ojados G., Bermúdez M. D.: Synergy between single-walled carbon nanotubes and ionic liquid in epoxy resin nanocomposites. Composites Part B: Engineering, 105, 149-159 (2016). https://doi.org/10.1016/j.compositesb.2016.08.044

[26] Liu L., Zheng Z., Gu C., Wang X.: The poly(urethaneionic liquid)/multi-walled carbon nanotubes composites. Composites Science and Technology, 70, 1697 1703 (2010).

https://doi.org/10.1016/j.compscitech.2010.06.007

[27] Zhao L., Li Y., Cao X., You J., Dong W.: Multifunctional role of an ionic liquid in melt-blended poly(methylmethacrylate)/multi-walled carbon nanotube nanocomposites. Nanotechnology, 23, 255702/1-255702/9 (2012). https://doi.org/10.1088/0957-4484/23/25/255702

[28] Torimoto T., Tsuda K., Okazaki K-I., Kuwabata S.: New frontiers in materials science opened by ionic liquids. Advanced Materials, 22, 1196-1221 (2010). https://doi.org/10.1002/adma.200902184

[29] Fukushima T., Kosaka A., Ishimura Y., Yamamoto T., Takigawa T., Ishii N., Aida T.: Molecular ordering of organic molten salts triggered by single-walled carbon nanotubes. Science, 300, 2072-2974 (2003). https://doi.org/10.1126/science.1082289

[30] Choi S. U. S.: Nanofluids: From vision to reality through research. Journal of Heat Transfer, 131, 033106/1033106/9 (2009).

https://doi.org/10.1115/1.3056479

[31] Zhou X., Wu T., Ding K., Hu B., Hou M., Han B.: Dispersion of graphene sheets in ionic liquid $\left[\mathrm{bmim}^{\mathrm{m}}\right]\left[\mathrm{PF}_{6}\right]$ stabilized by an ionic liquid polymer. Chemical Communications, 46, 386-388 (2010).

https://doi.org/10.1039/b914763b
[32] Fang D., Zhou C., Liu G., Luo G., Gong P., Yang Q., Niu Y., Li G.: Effects of ionic liquids and thermal annealing on the rheological behavior and electrical properties of poly(methyl methacrylate)/carbon nanotubes composites. Polymer, 148, 68-78 (2018).

https://doi.org/10.1016/j.polymer.2018.05.051

[33] Sanes J., Avilés M-D., Saurín N., Espinosa T., Carrión F-J., Bermúdez M. D.: Synergy between graphene and ionic liquid lubricant additives. Tribology International, 116, 371-382 (2017). https://doi.org/10.1016/j.triboint.2017.07.030

[34] Arribas A., Bermudez M. D., Carrión F. J., Espejo C., Martínez-López E., Sanes J.: Study of the scratch resistance of polymethylmethacrylate-single walled carbon nanotubes nanocomposites. Effect of modification by a room temperature ionic liquid. in 'Materials and surface engineering: Research and development' (ed.: Davim J. P.) Woodhead, Oxford, 1-22 (2011).

[35] Yang S-Y., Lin W-N., Huang Y-L., Tien H-W., Wang J-Y., Ma C-C. M., Li S-M., Wang Y-S.: Synergetic effects of graphene platelets and carbon nanotubes on the mechanical and thermal properties of epoxy composites. Carbon, 49, 793-803 (2011). https://doi.org/10.1016/j.carbon.2010.10.014

[36] Jyoti J., Babal A. S., Sharma S., Dhakate S. R., Singh B. P.: Significant improvement in static and dynamic mechanical properties of graphene oxide-carbon nanotube acrylonitrile butadiene styrene hybrid composites. Journal of Materials Science, 53, 2520-2536 (2018). https://doi.org/10.1007/s10853-017-1592-6

[37] Delva L., Ragaert K., Allaer K., Gaspar-Cunha A., Degrieck J., Cardon L.: Influence of twin-screw configuration on the mechanical and morphological properties of polypropylene-clay composites. International Journal of Materials and Product Technology, 52, 176-192 (2016).

https://doi.org/10.1504/IJMPT.2016.073631

[38] Hwang S-H., Kim B-J., Baek J-B., Shin H. S., Bae I-J., Lee S-Y., Park Y-B.: Effects of process parameters and surface treatments of graphene nanoplatelets on the crystallinity and thermomechanical properties of polyamide 6 composite fibers. Composites Part B: Engineering, 100, 220-227 (2016).

https://doi.org/10.1016/j.compositesb.2016.06.062

[39] Lertwimolnun W., Vergnes B.: Effect of processing conditions on the formation of polypropylene/organoclay nanocomposites in a twin screw extruder. Polymer Engineering and Science, 46, 314-323 (2006). https://doi.org/10.1002/pen.20458

[40] Lertwimolnun W., Vergnes B.: Influence of screw profile and extrusion conditions on the microstructure of polypropylene/organoclay nanocomposites. Polymer Engineering and Science, 47, 2100-2109 (2007). https://doi.org/10.1002/pen.20934 
[41] Lu J., Obara S., Ioannidis N., Suwardie J., Gogos C., Kikuchi S.: Understanding the processing window of hypromellose acetate succinate for hot-melt extrusion, Part I: Polymer characterization and hot-melt extrusion. Advances in Polymer Technology, 37, 154-166 (2016). https://doi.org/10.1002/adv.21652

[42] Treece M. A., Zhang W., Moffitt R. D., Oberhauser J. P.: Twin-screw extrusion of polypropylene-clay nanocomposites: Influence of masterbatch processing, screw rotation mode, and sequence. Polymer Engineering and Science, 47, 898-911 (2007). https://doi.org/10.1002/pen.20774

[43] Godavarti S. Karwe M. V.: Determination of specific mechanical energy distribution on a twin-screw extruder. Journal of Agricultural Engineering Research, 67, 277-287 (1997). https://doi.org/10.1006/jaer.1997.0172

[44] Gropper M., Moraru C. I., Kokini J. L.: Effect of specific mechanical energy on properties of extruded protein-starch mixtures. Cereal Chemistry, 79, 429-433 (2002). https://doi.org/10.1094/CCHEM.2002.79.3.429

[45] Domenech T., Peuvrel-Disdier E., Vergnes B.: Influence of twin-screw processing conditions on structure and properties of polypropylene - Organoclay nanocomposites. International Polymer Processing, 27, 517-526 (2012).

https://doi.org/10.3139/217.2591
[46] Domenech T., Peuvrel-Disdier E., Vergnes B.: The importance of specific mechanical energy during twin screw extrusion of organoclay based polypropylene nanocomposites. Composites Science and Technology, 75, 7-14 (2013). https://doi.org/10.1016/j.compscitech.2012.11.016

[47] Villmow T., Kretzschmar B., Pötschke P.: Influence of screw configuration, residence time, and specific mechanical energy in twin-screw extrusion of polycaprolactone/multi-walled carbon nanotube composites. Composites Science and Technology, 70, 2045-2055 (2010). https://doi.org/10.1016/j.compscitech.2010.07.021

[48] Mohamed A. A., Hussain S., Alamri M. S., Ibraheem M. A., Abdo Qasem A. A.: Specific mechanical energy and thermal degradation of poly(lactic acid) and poly(caprolactone)/date pits composites. International Journal of Polymer Science, 2018, 7493545/1-7493545/10 (2018). https://doi.org/10.1155/2018/7493545

[49] Médéric P., Aubry T., Razafinimaro T.: Structural and rheological properties as a function of mixing energy for polymer/layered silicate nanocomposites. International Polymer Processing, 24, 261-266 (2009). https://doi.org/10.3139/217.2247

[50] Moulder J. F., Stickle W. F., Sobol P. E., Bomben K. D.: Handbook of X-ray photoelectron spectroscopy. Perkin Elmer, Eden Prairie (1992).

[51] Gao X., Isayev A. I., Yi C.: Ultrasonic treatment of polycarbonate/carbon nanotubes composites. Polymer, 84, 209-222 (2016).

https://doi.org/10.1016/j.polymer.2015.12.051 